\title{
Neuroanatomical distribution of the enkephalinergic and tachykininergic systems in the alpaca brainstem: an immunohistochemical study
}

\author{
Pablo Sánchez ${ }^{1}$, Manuel Lisardo Sánchez ${ }^{1}$, Arturo Mangas ${ }^{1}$, Eliana de Souza ${ }^{1}$, \\ Luis Angel Aguilar², Rafael Coveñas ${ }^{1,3}$
}

\author{
${ }^{1}$ Institute of Neuroscience of Castilla y León (INCYL), Laboratory of Neuroanatomy \\ of the Peptidergic Systems (Lab. 14), University of Salamanca, Salamanca, Spain \\ ${ }^{2}$ San Ignacio de Loyola University (USIL), Faculty of Health Sciences, Lima, Peru \\ ${ }^{3}$ Grupo GIR USAL: BMD (Bases Moleculares del Desarrollo)
}

\begin{abstract}
Introduction. A recent study has shown a close neuroanatomical relationship between the enkephalinergic (methionine-enkephalin) and tachykininergic (substance P) systems in the alpaca diencephalon. In this study, our aim is to show this relationship in the alpaca brainstem.

Material and methods. Using an immunohistochemical technique, the distribution of immunoreactive (Ir) fibers and cell bodies containing substance P (SP) or methionine-enkephalin (MET) has been studied in the alpaca brainstem. Five adult males were used; brain tissue was fixed and processed by standard methods.

Results. SP- and MET-Ir fibers showed a widespread and similar distribution in the mesencephalon, pons and medulla oblongata. The co-localization of fibers containing SP or MET was found in most of the nuclei/tracts of the alpaca brainstem. This close neuroanatomical relationship suggests multiple physiological interactions between both neuropeptides. The distribution of the cell bodies containing SP was very restricted (cell bodies were only observed in a few nuclei located in the mesencephalon and medulla oblongata), whereas MET-Ir perikarya showed a moderately widespread distribution in the mesencephalon, pons and medulla oblongata. Conclusions. This study increases the knowledge on the neuroanatomical distribution/relationship of the tachykininergic (SP) and enkephalinergic (MET) systems in the alpaca central nervous system. (Folia Histochemica et Cytobiologica 2021, Vol. 59, No. 3, 145-156
\end{abstract}

Key words: substance P; methionine-enkephalin; mesencephalon; pons; medulla oblongata; Lama pacos, IHC

\section{Introduction}

The brainstem plays a fundamental role by conducting the information of the brain with the rest of the body and vice vers $a$ and, in addition, it integrates the

Correspondence address: Dr. Manuel Lisardo Sánchez Universidad de Salamanca, Instituto de Neurociencias de Castilla y León (INCYL)

Laboratorio de Neuroanatomía de los Sistema Peptidérgicos

(Lab. 14) c/Pintor Fernando Gallego, 1

37007-Salamanca, Spain

phone: +34 923294400 ext. 1856, fax: +34 923294549

e-mail: lisardosanchez8@gmail.com information of the cardiovascular/respiratory systems, is involved in pain perception and its motor neurons send outputs through the cranial nerves [1].

Many studies have been performed to know the distribution/function of substance P (SP) in the mammalian central and peripheral nervous systems [2]. SP belongs to the tachykinin family of peptides, like neurokinin $\mathrm{A}$, and both peptides arise from the polyprotein precursor produced by differential splicing of the pre-protachykinin A gene [2]. SP, mainly via the neurokinin-1 receptor, plays many functional/ /pathophysiological roles in inflammation-associated vasodilation, pain perception, immune responses,

This article is available in open access under Creative Common Attribution-Non-Commercial-No Derivatives 4.0 International (CC BY-NC-ND 4.0) license, allowing to download articles and share them with others as long as they credit the authors and the publisher, but without permission to change them in any way or use them commercially. 
learning, nausea, stress, anxiety, cancer and depression $[3,4]$. SP is widely distributed through the nervous system (e.g., thalamus, hypothalamus, brainstem, spinal cord) [5-8].

Methionine-enkephalin (MET) is an opioid pentapeptide derived from the pro-enkephalin and pro-opiomelanocortin precursors after their proteolytic cleavage $[9,10]$. MET is widely visualized through the central nervous system (CNS) of mammals (e.g., cat, dog, monkey), suggesting the multiple physiological functions in which the peptide is involved [11-13]. Thus, MET has been located in nervous system regions involved in the transmission and control of pain messages (e.g., thalamus, brainstem reticular formation, raphe nuclei, periaqueductal gray, spinal cord). MET is also involved in analgesia, stress, respiratory and cardiovascular mechanisms, feeding behavior, peristalsis and memory [14].

The ungulate alpaca (Lama pacos) belongs to the family of Camelidae which is a member of the order Artiodactyla. The alpaca has precious wool that is greatly demanded for producing a high quality fiber. Due to the economic importance, many studies have been focused on the hormonal processes involved in reproductive mechanisms $[15,16]$. Alpacas can live from the sea level to $5,000 \mathrm{~m}$ altitude, indicating that this species has special physiological adjustment mechanisms, as are those related to providing sufficient blood flow to the brain and the implication of these unique features in the neuroanatomical organization of some CNS nuclei. In addition to those works focused on the alpaca reproductive mechanisms, several studies have been previously performed on the neuroanatomical location of neuropeptides (calcitonin gene-related peptide, somatostatin-28 (1-12), neurotensin, leucine-enkephalin, alpha-neo-endorphin, adrenocorticotropic hormone (18-39), beta-endorphin (1-27)) in the alpaca brainstem [17-22]. In addition, a recent study has shown a close neuroanatomical relationship between the enkephalinergic (methionine-enkephalin) and tachykininergic (substance $\mathrm{P}$ ) systems in the alpaca diencephalon and the presence of some neuropeptides (e.g., neurotensin) has also been reported in this region of the alpaca CNS [5, 23]. To our best knowledge no immunohistochemical study on the distribution of SP and MET has been carried out in the alpaca brainstem. Therefore, the main goal of this work is to study, for the first time, the presence of immunoreactive structures containing SP/MET in the alpaca brainstem and to know whether in this brain region a close neuroanatomical relationship between both systems occurs, in addition to the diencephalon. Another goal is to compare the distribution of both peptides with that described for other neuropeptides in the alpaca brainstem and to compare the presence of SP/MET in the alpaca with the presence observed for both peptides in the same brain region of other mammals.

\section{Material and methods}

Animals. As previously reported [5], the use of animals in this study along with procedures of their maintenance, experimental design, protocols and methodology were carried out according to the principles of laboratory animal care and performed under the advices of the ethical and legal guidance of Peruvian and Spanish laws. This work was as well approved by the Research Commission of the Cayetano Heredia Peruvian University (Lima, Peru). Because previous studies on the distribution of neuropeptides were carried out in males [17-22] and, in order to compare the results observed here with previous works performed in the alpaca brainstem [17-22], the present study was carried out in male alpacas. Five adult alpacas (Lama pacos) $(70-80 \mathrm{~kg}$; 5-8 years) were obtained from the Cayetano Heredia Peruvian University (Faculty of Veterinary Medicine and Animal Sciences). As previously reported [17-22], alpacas were maintained at $0 \mathrm{~m}$ altitude, under standard conditions of temperature and lightning and were provided with free access to food and water and, from birth to the moment of the perfusion; animals were kept at sea level.

Tissue preparation. As previously reported [5, 17-20], animals were deeply anasthetized with ketamine $(10 \mathrm{mg} / \mathrm{kg})$ and xylazine $(4 \mathrm{mg} / \mathrm{kg})$ both administered intravenously. Afterwards, they were heparinized and perfused with $3 \mathrm{~L}$ of cold $\mathrm{NaCl}(0.9 \%)$ through the carotid artery. This pre-rinse was straight away followed by infusion of the fixative: $5 \mathrm{~L}$ of cold paraformaldehyde (4\%) diluted in $0.15 \mathrm{M}$ phosphate-buffered saline (PBS) ( $\mathrm{pH}$ 7.2). Once brainstems were dissected out, they were post-fixed overnight in the same fixative solution and cryoprotected, via immersion in sucrose solutions at increasing concentrations (10-30\%), until they sank. Making use of a cryostat, frontal sections were cut $(50 \mu \mathrm{m})$ and kept in PBS at $4^{\circ} \mathrm{C}$. Two of six sections were used for immunohistochemistry: section 1, for anti-MET staining; section 2, for Nissl staining to identify/delimited the brainstem nuclei or for histological controls; section 3, for anti-SP staining; sections 4-6 were kept for other experimental purposes. The distance between sections 1 and 7 (and so on, kept in the same container) was about $300 \mu \mathrm{m}$. Thus, sections kept in containers 1 and 3 were respectively used for anti-MET and anti-SP. In each container, 55-60 frontal sections/animal were collected.

Immunohistochemistry and specificity of the antisera. As formerly reported $[5,17-20]$ and to prevent possible interference with endogenous peroxidase, free-floating sections were treated with a mixture of $\mathrm{NaOH}, \mathrm{NH}_{3}$ and $\mathrm{H}_{2} \mathrm{O}_{2}(20 \mathrm{~min})$. 
Sections were then washed with PBS $(3 \times 10 \mathrm{~min})$ and to improve antibody penetration free-floating sections were pre-incubated (30 $\mathrm{min}$ ) in a PBS solution containing normal horse serum (1\%) and Triton X-100 (0.3\%). Then, sections were incubated overnight $\left(4^{\circ} \mathrm{C}\right)$ in the latter solution supplemented with anti-SP antiserum $(1 / 3,000)$ or anti-MET antiserum $(1 / 3,000)$. Sections were washed in PBS (30 min) and incubated $(1 \mathrm{~h})$ in biotinylated anti-rabbit IgG (1/200). Later, sections were treated $(1 \mathrm{~h})$ with Vectastain $\mathrm{ABC}$ reagent $(1 / 100)$ and washed in PBS (30 min) and Tris- $\mathrm{HCl}$ buffer ( $\mathrm{pH} 7.6 ; 10 \mathrm{~min}$ ). Finally, the tissue bound peroxidase was developed (using $\mathrm{H}_{2} \mathrm{O}_{2}$ and 3, 3'-diaminobenzidine as chromogen), sections were rinsed (PBS) and coverslipped with PBS and glycerol (1/1).

The polyclonal primary antibodies used here (anti-SP; anti-MET; obtained at the laboratory of Professor Gérard Tramu, University of Bordeaux I, France), were raised in rabbits against immunogens assembled by coupling the full synthetic SP or MET to a carrier protein (human serum albumin) with glutaraldehyde, as formerly reported $[5,13$, 24]. Rabbits were immunized with immunogens emulsified with Freund's complete adjuvant and provided with booster doses of Freund's incomplete adjuvant at intervals of two weeks. Ten days, after three of such booster injections, plasma from rabbits was obtained and periodically thereafter. To avoid non-specific immunoreactivity due to the anticarrier antibodies, rabbit antisera were preabsorbed with the coupling agent and the carrier protein, being this preabsorption performed prior to the immunohistochemical technique. The immunological properties of the anti-SP and anti-MET antisera have been previously reported $[5,10,13$, 25, 26]. The anti-MET used in this study was purified by affinity chromatography $[5,10,13]$. In addition, in this study, three histological controls were performed. Thus, primary antibody was treated with an excess $(100 \mu \mathrm{g} / \mathrm{ml}$ of diluted antiserum) of the same synthetic antigen (e.g., MET to anti-MET serum) and the first antiserum was omitted in the first incubation bath (no immunoreactivity was found in both cases). Moreover, primary antibodies were preabsorbed with heterologous antigens (e.g., neurokinin A to anti-SP serum; leucine-enkephalin to anti-MET serum): this preabsorption did not block the staining.

Mapping. This was performed by following frontal planes of the alpaca brainstem (the brain atlas used here is available from the Mammalian Brain Collections of the University of Wisconsin, Madison, USA). For mapping and nomenclature of the brainstem nuclei, we also followed previous published works performed in this camelid [17-22]. In addition, contiguous sections to those reacted for SP or MET were stained with cresyl violet to delineate the brainstem nuclei in which immunoreactive structures were observed.

As previously reported [5, 17-22], immunoreactive fibers were graded into four categories: single (a few immunoreac- tive fibers; Fig. 2b), low, moderate (Fig. 2d) and high (Fig. $4 \mathrm{~b}, \mathrm{~d})$. To determine the density of the immunoreactive fibers, sections were viewed (at a constant magnification) with reference to photographs in which low, moderate of high densities were previously determined [5, 17-22]. The density of the immunoreactive cell bodies was considered high (> 20 perikarya/section), moderate (10-20 perikarya/ /section) and low (< 10 perikarya/section). Immunoreactive cell bodies size was measured following the protocol described by Marcos et al. [24]. Using a micrometer grid, the size of cell bodies was measured with the nucleus in the focal plane, and, as previously reported [5, 17-22], cell bodies with $<15 \mu \mathrm{m}$ diameter were considered small, perikarya with a diameter between $15-25 \mu \mathrm{m}$ were contemplated as medium sized, and those with a $>25 \mu \mathrm{m}$ diameter were considered large.

Using an Olympus DP-50 digital camera (Olympus, Tokyo, Japan) attached to a Kyowa Unilux 12 microscope (Kyowa Optical, Sagamihara, Japan), photomicrographs were taken. Adobe Photoshop CS6 software was used to adjust contrast and brightness.

\section{Results}

\section{General considerations}

Figures 1-4 and Table 1 show the presence and density of the immunoreactive structures (fibers and cell bodies) containing SP/MET observed in 44 tracts/nuclei of the alpaca brainstem. SP- and MET-immunoreactive fibers showed a widespread distribution. Thus, SP-immunoreactive fibers were observed in 42 (95.45\%) of 44 tracts/nuclei, whereas fibers containing MET were found in 41 of them $(93.18 \%)$. In the mesencephalon, SP- and MET-immunoreactive fibers were visualized in all tracts/nuclei (13 of $13,100 \%)$; in the pons, in 13 of 13 tracts/nuclei (for SP-immunoreactive fibers, $100 \%$ ) and in 12 of 13 (for MET-immunoreactive fibers, $92.30 \%$ ), and in the medulla oblongata in 16 tracts/nuclei of $18(88.88 \%)$ for both SP- and MET-immunoreactive fibers. Thus, in the brainstem, the distribution of SP- and MET-immunoreactive fibers was similar (Fig. 1; Table 1). This means that a close neuroanatomical relationship between SP-and MET-immunoreactive fibers occurs. Finally, in the alpaca brainstem, the density of the SP-immunoreactive fibers is a little higher when compared with the density observed for the MET-immunoreactive fibers (Fig. 1; Table 1).

In the alpaca brainstem, MET-immunoreactive perikarya were observed in 22 of the 44 brainstem nuclei $(50 \%)$, whereas cell bodies containing SP were visualized in 3 nuclei $(6.81 \%)$. In the mesencephalon, SP-immunoreactive cell bodies were found in 2 nuclei $(15.38 \%)$ and those containing MET in 


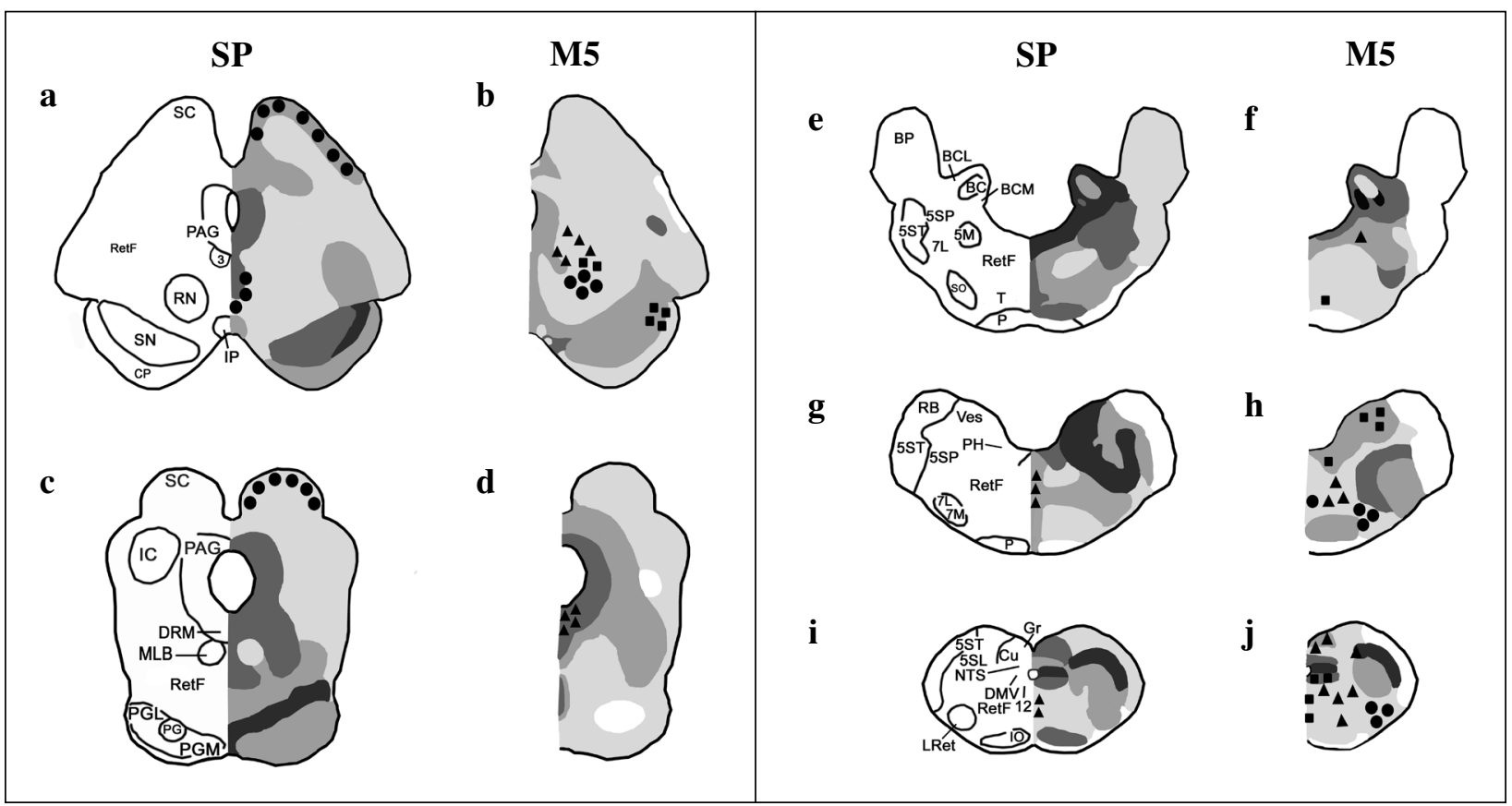

Figure 1. Distribution of substance P (SP) and methionine-enkephalin (M5)-immunoreactive fibers and cell bodies in frontal planes of the alpaca brainstem (a-j) from rostral (a) to caudal (j) levels. Cell bodies containing the peptides are represented by closed circles (high density), triangles (moderate density) and squares (low density), whereas immunoreactive fibers are represented by slightly dark (single axons), moderately dark (low density), strongly dark (moderate density), and black (high density). 3 - oculomotor nucleus; 4 - trochlear nucleus; 12 - hypoglossal nucleus; $5 \mathrm{M}$ - motor trigeminal nucleus; 5SL - laminar spinal trigeminal nucleus; 5SP — alaminar spinal trigeminal nucleus, parvocellular division; 5ST — spinal trigeminal tract; 7L — facial nucleus, lateral division; 7M — facial nucleus, medial division; AP — area postrema; $\mathrm{BC}$ brachium conjunctivum: $\mathrm{BCL}$ - marginal nucleus of the brachium conjunctivum, lateral division; $\mathrm{BCM}$ - marginal nucleus of the brachium conjunctivum, medial division; $\mathrm{BP}$ - brachium pontis; $\mathrm{CAE}$ - locus coeruleus; $\mathrm{CP}$ - cerebral peduncle; $\mathrm{Cu}$ - cuneate nucleus; $\mathrm{Cx}$ - external cuneate nucleus; Cuc - cuneate nucleus, caudal division; DMV - motor dorsal nucleus of the vagus; DRM - dorsal nucleus of the raphe; $\mathrm{Gr}$ - gracile nucleus; IC — inferior colliculus; IO — inferior olive; IP — interpeduncular nucleus; LRet — lateral reticular nucleus; MLB — medial longitudinal bundle; NTS — nucleus of the solitary tract; P — pyramidal tract; PAG — periaqueductal gray; PG — pontine gray; PGL — pontine gray, lateral division; PGM — pontine gray, medial division; $\mathrm{PH}$ - nucleus praepositus hypoglossi; RB — restiform body; RetF — reticular formation; RN — red nucleus; S — solitary tract; SC — superior colliculus; SN — substantia nigra; SO — superior olive; $\mathrm{T}$ - nucleus of the trapezoid body; Ves — vestibular nuclei.

7 nuclei $(53.84 \%)$; in the pons no immunoreactive cell body containing SP was observed, whereas in 5 nuclei $(38.46 \%)$ MET-immunoreactive perikarya were visualized, and in the medulla oblongata cell bodies were found in one nucleus (for SP, $5.55 \%$ ) and in 10 nuclei (for MET, 55.55\%). Thus, in the alpaca brainstem the distribution and number of cell bodies containing MET is higher than those containing SP. The morphological characteristics of the MET- and SP-immunoreactive cell bodies (size, shape, number of dendrites) are shown in Table 2. In general, in the five alpacas studied the density and distribution of the MET- and SP-immunoreactive cell bodies and fibers observed in the brainstem were quite similar.

It is important to note that in different regions of the same nucleus, two densities (e.g., moderate and high; single and low) can be observed (Table 1). In these cases, to obtain the percentages appearing below the highest density was chosen.

\section{Mesencephalon}

MET-immunoreactive cell bodies were observed in the oculomotor nucleus, trochlear nucleus, dorsal nucleus of the raphe, periaqueductal gray, reticular formation, red nucleus and substantia nigra, whereas SP-immunoreactive cell bodies were found in the superior colliculus and reticular formation (Figs. 1, 2b, c, g, 3b; Table 1).

Fibers containing SP or MET were observed in all mesencephalic tracts/nuclei and hence a similar distribution of both immunoreactive fibers was visualized (Figs. 1, 2d-f, 3c-g; Table 1). Single SP- and MET-immunoreactive fibers were respectively found in $2(15.38 \%)$ and $4(30.76 \%)$ tract/nuclei; a low density in 3 tracts/nuclei (for both neuropeptides, 


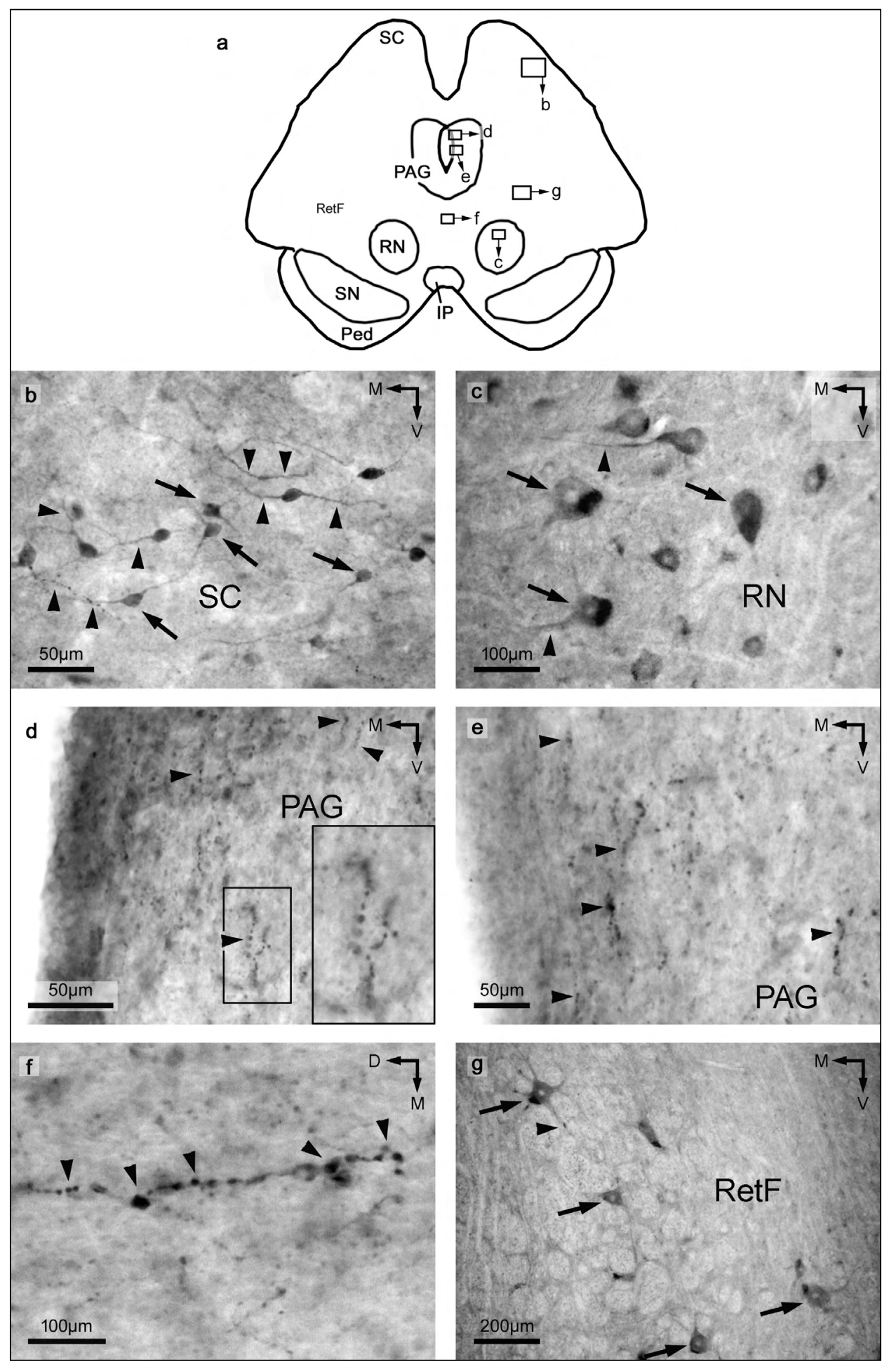

Figure 2. SP- and MET-immunoreactive (Ir) cell bodies and fibers/dendrites in the alpaca mesencephalon. A. Frontal section of the alpaca mesencephalon. For the nomenclature of the nuclei, see Figure 1. The photographs shown in b-g were taken from the regions delimited by the rectangles in a (indicated as Fig. b, c, d, e, f and g). B. SP-Ir cell bodies (arrows) located in the superior colliculus (SC). Arrowheads: fibers or dendrites. C. MET-Ir cell bodies (arrows) located in the red nucleus (RN). Arrowheads: dendrites. D. SP-Ir fibers (arrowheads) located in the periaqueductal gray (PAG). The region delimited by the left rectangle is showed at higher magnification. E. MET-Ir fibers (arrowheads) in the periaqueductal gray (PAG). F. SP-Ir fibers (arrowheads) located in the midline. G. MET-Ir cell bodies (arrows) in the reticular formation (RetF). Arrowhead: dendrite. D - dorsal; M - medial. V - ventral. 


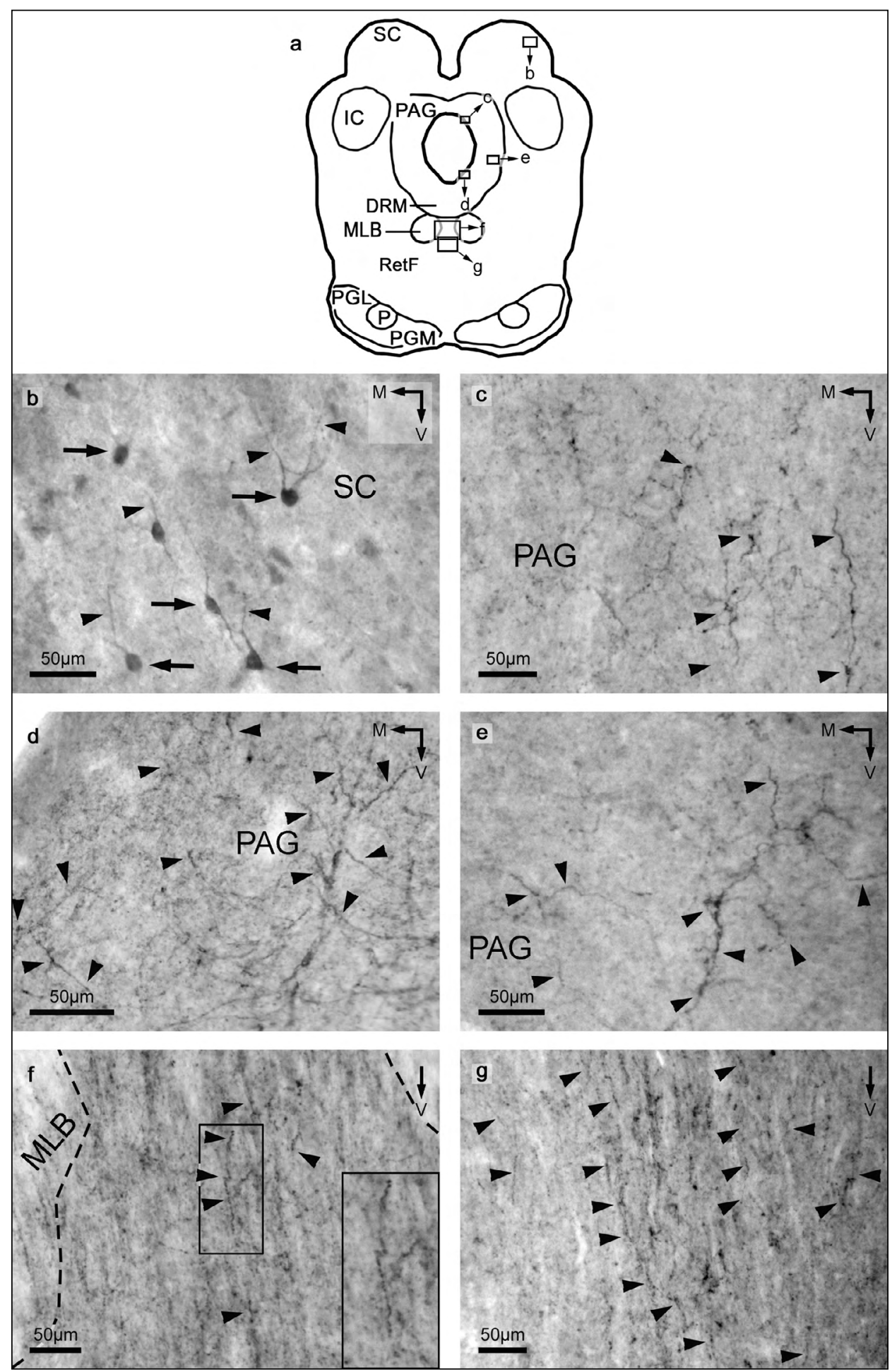

Figure 3. Immunoreactive (Ir) fibers/dendrites and cell bodies containing SP or MET in the alpaca mesencephalon. A. Frontal section of the alpaca mesencephalon. For the nomenclature of the nuclei, see Figure 1. The photographs shown in b-g were taken from the regions delimited by the rectangles in a (indicated as Fig. b, c, d, e, f and g). B. SP-Ir cell bodies (arrows) located in the superior colliculus (SC). Arrowheads: dendrites. C. MET-Ir fibers (arrowheads) in the periaqueductal gray (PAG). D. SP-Ir fibers (arrowheads) located in in the periaqueductal gray (PAG). E. MET-Ir fibers (arrowheads) located in in the periaqueductal gray (PAG). F. SP-immunoreactive fibers (arrowheads) in the upper midline. The region delimited by the left rectangle is showed at higher magnification. MLB: medial longitudinal bundle. G. MET-Ir fibers (arrowheads) in the midline. $\mathrm{M}-$ medial. $\mathrm{V}$ - ventral. 
a
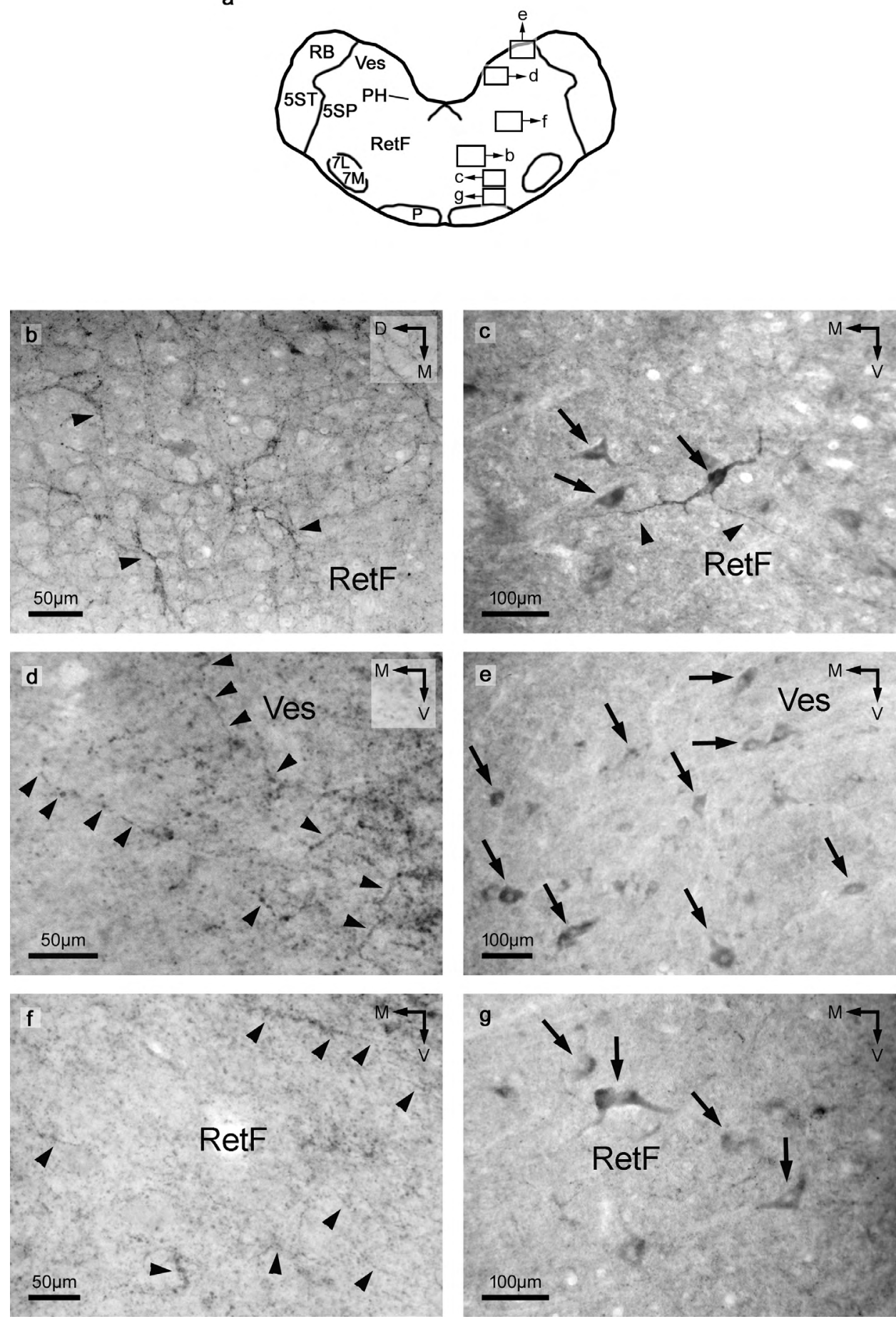

Figure 4. SP- and MET-immunoreactive (Ir) fibers/dendrites and cell bodies in the alpaca medulla oblongata. A. Frontal section of the alpaca medulla oblongata. For the nomenclature of the nuclei, see Figure 1. The photographs shown in b-g were taken from the regions delimited by the rectangles in a (indicated as Fig. b, c, d, e, f and g). B. SP-Ir fibers (arrowheads) located in the reticular formation (RetF). C. MET-Ir cell bodies (arrows) in the reticular formation (RetF). Arrowheads: dendrites. D. SP-Ir fibers (arrowheads) located in the vestibular nuclei (Ves). E. MET-Ir cell bodies (arrows) located in the vestibular nuclei (Ves). F. SP-Ir fibers (arrowheads) in the reticular formation (RetF). G. MET-Ir cell bodies (arrows) in the reticular formation (RetF). D - dorsal. $\mathrm{M}$ - medial. V - ventral. 
Table 1. Alpaca brainstem: distribution and density of SP- and MET-immunoreactive cell bodies and fibers

\begin{tabular}{|c|c|c|c|c|}
\hline \multicolumn{5}{|c|}{ Mesencephalon } \\
\hline & \multicolumn{2}{|c|}{ SP } & \multicolumn{2}{|c|}{ MET } \\
\hline Nucleus & CB & Fibers & CB & Fibers \\
\hline 3 & - & ++ & ++ & $\mathrm{s} /+$ \\
\hline 4 & - & ++ & +++ & $\mathrm{s}$ \\
\hline BC & - & + & - & $\mathrm{s}$ \\
\hline $\mathrm{BCL}$ & - & +++ & - & ++ \\
\hline BCM & - & +++ & - & $++/+++$ \\
\hline DRM & - & ++ & ++ & ++ \\
\hline IC & - & $\mathrm{s}$ & - & $\mathrm{s} /+$ \\
\hline IP & - & + & - & $\mathrm{s} /+++$ \\
\hline PAG & - & ++ & $+/++$ & $+/++$ \\
\hline RetF & +++ & $\mathrm{s} /++$ & $+/+++$ & $\mathrm{s} /+$ \\
\hline $\mathrm{RN}$ & - & $\mathrm{s}$ & +++ & $\mathrm{s}$ \\
\hline $\mathrm{SC}$ & +++ & $\mathrm{s} /+$ & - & $\mathrm{s}$ \\
\hline SN & - & $++/+++$ & ++ & $+/++$ \\
\hline \multicolumn{5}{|c|}{ Pons } \\
\hline & \multicolumn{2}{|c|}{ SP } & \multicolumn{2}{|c|}{ MET } \\
\hline Nucleus & CB & Fibers & CB & Fibers \\
\hline $5 \mathrm{M}$ & - & ++ & + & + \\
\hline $5 \mathrm{SP}$ & - & $+/+++$ & ++ & $\mathrm{s} /++$ \\
\hline $7 \mathrm{~L}$ & - & $+/++$ & +++ & $\mathrm{s}$ \\
\hline $7 \mathrm{M}$ & - & + & +++ & $\mathrm{s}$ \\
\hline BP & - & s & - & - \\
\hline CAE & - & $++/+++$ & - & $\mathrm{s}$ \\
\hline MLB & - & $\mathrm{s}$ & - & s \\
\hline PG & - & + & - & $\mathrm{s}$ \\
\hline PGL & - & + & - & $\mathrm{s}$ \\
\hline
\end{tabular}

\begin{tabular}{|c|c|c|c|c|}
\hline PGM & - & + & - & $\mathrm{s}$ \\
\hline RetF & - & $\mathrm{s} /+++$ & - & $\mathrm{s} /++$ \\
\hline SO & - & + & - & ++ \\
\hline $\mathrm{T}$ & - & $+/++$ & ++ & $\mathrm{s}$ \\
\hline \multicolumn{5}{|c|}{ Medulla oblongata } \\
\hline & \multicolumn{2}{|c|}{ SP } & \multicolumn{2}{|c|}{ MET } \\
\hline Nucleus & CB & Fibers & $\mathbf{C B}$ & Fibers \\
\hline 12 & - & ++ & ++ & $+/++$ \\
\hline $5 \mathrm{SL}$ & - & +++ & + & $\mathrm{s} /+++$ \\
\hline $5 \mathrm{ST}$ & - & $\mathrm{s}$ & - & $\mathrm{s}$ \\
\hline AP & - & ++ & - & +++ \\
\hline $\mathrm{Cu}$ & - & ++ & + & $\mathrm{s}$ \\
\hline $\mathrm{Cuc}$ & - & + & +++ & s \\
\hline $\mathrm{Cx}$ & - & ++ & ++ & $\mathrm{s}$ \\
\hline DMV & - & +++ & - & +++ \\
\hline $\mathrm{Gr}$ & - & ++ & + & + \\
\hline IO & - & ++ & - & $\mathrm{s}$ \\
\hline LRet & - & + & +++ & $\mathrm{s}$ \\
\hline NTS & - & + & - & ++ \\
\hline $\mathrm{P}$ & - & - & - & - \\
\hline PH & - & ++ & ++ & + \\
\hline $\mathrm{RB}$ & - & - & - & - \\
\hline RetF & $+/++$ & $\mathrm{s} /+++$ & $+/+++$ & $\mathrm{s} /++$ \\
\hline $\mathrm{S}$ & - & $\mathrm{s}$ & - & $\mathrm{s}$ \\
\hline Ves & - & $+/+++$ & $+/+++$ & $\mathrm{s} /+$ \\
\hline
\end{tabular}

$\mathrm{CB}-$ cell bodies $(+++$ : high density; ++ : moderate density; + : low density; - : no immunoreactivity). Fibers $(+++$ : high density; ++ : moderate density; + : low density; s: single; - : no immunoreactivity). For nomenclature of the nuclei, see list of abbreviations.

$23.07 \%)$; a moderate density in $5(38.46 \%)$ and $4(30.76 \%)$ mesencephalic nuclei, and a high density in $3(23.07 \%)$ and $2(15.38 \%)$ nuclei (Table 1$)$.

\section{Pons}

No immunoreactive cell body containing SP was observed, whereas perikarya containing MET were found in the motor trigeminal nucleus, alaminar spinal trigeminal nucleus (parvocellular division), lateral and medial divisions of the facial nucleus and nucleus of the trapezoid body (Fig. 1; Table 1).

SP- and MET-immunoreactive fibers showed a similar distribution in the alpaca pons, although the density of the fibers containing MET was lower than that observed for SP (Fig. 1; Table 1). Thus, single SPand MET-immunoreactive fibers were respectively found in $2(15.38 \%)$ and $8(61.53 \%)$ tracts/nuclei; a low density in $5(38.46 \%)$ and $1(7.69 \%)$ nuclei; a moderate density in 3 pons nuclei (for both neuropeptides, $23.07 \%)$, and a high density in $3(23.07 \%)$ and 0 nuclei (Fig. 1; Table 1).

\section{Medulla oblongata}

Cell bodies containing SP were only observed in the reticular formation, whereas MET-immunoreactive perikarya were found in the external cuneate nucleus, lateral reticular nucleus, reticular formation, vestibular nuclei, cuneate nucleus, hypoglossal nucleus, laminar spinal trigeminal nucleus, caudal division of the cuneate nucleus, gracilis nucleus and nucleus praepositus hypoglossi (Figs. 1, 4c, e, g; Table 1).

The distribution of fibers containing SP or MET was similar. Both peptides were absent in the pyramidal tract and restiform body, but in the other 16 tracts/ 
Table 2. Alpaca brainstem: morphological characteristics of the MET- and SP-immunoreactive cell bodies

\begin{tabular}{|c|c|c|c|c|}
\hline Nucleus & Density & Size & Shape & Dendritic processes \\
\hline \multicolumn{5}{|c|}{ MET- immunoreactive cell bodies } \\
\hline 3 & ++ & Medium & Pyriform, oval & $0-1$ \\
\hline 4 & +++ & Medium & Pyriform, oval & $0-1$ \\
\hline $5 \mathrm{M}$ & + & Large & Polygonal & $2-3$ \\
\hline $5 \mathrm{SL}$ & + & Large & Polygonal & 2 \\
\hline $5 \mathrm{SP}$ & ++ & Large & Oval & 1 \\
\hline $7 \mathrm{~L}$ & +++ & Medium & Oval & 1 \\
\hline $7 \mathrm{M}$ & +++ & Medium & Oval & 1 \\
\hline 12 & ++ & Medium & Oval & 1 \\
\hline $\mathrm{Cu}$ & + & Medium & Polygonal, oval & $1-2$ \\
\hline $\mathrm{Cuc}$ & +++ & Medium & Polygonal, oval & $1-2$ \\
\hline $\mathrm{Cx}$ & ++ & Medium & Polygonal, oval & $1-2$ \\
\hline DRM & +++ & Small & Oval & $0-1$ \\
\hline $\mathrm{Gr}$ & + & Medium & Oval & $0-1$ \\
\hline LRet & +++ & Large & Polygonal & $2-3$ \\
\hline PAG & ++ & Small & Pyriform, oval & 1 \\
\hline $\mathrm{PH}$ & ++ & Large & Polygonal & $2-3$ \\
\hline RetF & +++ & Large & Polygonal, oval & $1-4$ \\
\hline RN & +++ & Large & Pyriform & 1 \\
\hline $\mathrm{SN}$ & ++ & Medium & Oval & $1-2$ \\
\hline $\mathrm{T}$ & ++ & Medium & Oval & 1 \\
\hline Ves & +++ & Medium & Oval & $1-2$ \\
\hline \multicolumn{5}{|c|}{ SP- immunoreactive cell bodies } \\
\hline RetF & $+/++/+++$ & Large & Pyriform, polygonal & $1-4$ \\
\hline SC & +++ & Small & Oval & 2 \\
\hline
\end{tabular}

+++ : high density; ++: moderate density; +: low density. For nomenclature of the nuclei, see list of abbreviations.

/nuclei immunoreactive fibers containing SP or MET were observed (Figs. 1, 4b, d, f; Table 1). Single SP- and MET-immunoreactive fibers were respectively found in $2(11.11 \%)$ and $7(38.88 \%)$ tracts/ nuclei; a low density in 3 nuclei (for both neuropeptides, $16.66 \%)$; a moderate density in $7(38.88 \%)$ and $3(16.66 \%)$ tracts/nuclei, and a high density in $4(22.22 \%)$ and $3(16.66 \%)$ nuclei (Fig. 1; Table 1$)$.

\section{Discussion}

\section{SP and MET in the alpaca brainstem}

For the first time, this study shows the mapping of the SP- and MET-immunoreactive cell bodies and fibers in the alpaca brainstem. The study increases the knowledge on the enkephalinergic and tachykininergic systems in the alpaca CNS, since a previous study has been reported on the distribution of SP and MET in the alpaca diencephalon
[5]. In both alpaca brainstem and diencephalon [5] a close neuroanatomical relationship between the tachykininergic (SP) and the enkephalinergic (MET) systems has been observed. This means that a functional relationship between both systems could also occur in both regions of the alpaca CNS and that mechanisms of intercellular communication (e.g., paracrine mechanism and/or synaptic contacts) between the enkephalinergic and tachykininergic systems, controlling many brainstem physiological actions, are possible. Moreover, in the mesencephalon, pons and medulla oblongata the presence of MET-immunoreactive perikarya is more widespread than that observed for cell bodies containing SP. This is in agreement with that reported in the alpaca diencephalon, in which the distribution of MET-immunoreactive cell bodies was also more widespread than that observed for cell bodies containing SP [5]. In addition, in the alpaca brainstem and diencephalon 
the number of cell bodies containing MET was higher than those containing SP.

The widespread distribution of the SP- and MET-immunoreactive structures in the alpaca brainstem suggests that both neuropeptides are involved in many physiological actions, in which SP and MET could interact. To date, the mechanisms of possible intercellular mechanisms between SP and MET are unknown, but this could occur through synaptic contacts and/ /or paracrine (volume transmission) mechanisms [5]. In the latter, neuropeptides are released into the extracellular region and diffuse longer distances until reaching their receptors; this is a slow mode of communication showing a high divergence degree [27]. In addition, neuropeptides could exert an autocrine mechanism. The brainstem has a key role in the relay of information between the brain and the spinal cord and it is known that some nuclei (e.g., periaqueductal gray, reticular formation, spinal trigeminal nucleus) are essential in the transmission of the nociceptive perception [28, 29]. In these nuclei both SP- and MET-immunoreactive structures have been observed and hence a neuroanatomical linkage between the transmission of pain via SP and the control of the pain stimuli via MET could occur. Moreover, the observation of cell bodies containing SP or MET in the rat lateral mammillary nucleus suggests that the neuropeptides are involved in head-direction and angular velocity [30], whereas the presence of a high density of SP-immunoreactive fibers in the locus coeruleus and superior colliculus indicates that SP is involved in arousal, anxiety, memory and in visual mechanisms [31-34]. Finally, the presence of SP- and MET-immunoreactive fibers in the alpaca area postrema, nucleus of the solitary tract, marginal nucleus of the brachium conjunctivum and motor dorsal nucleus of the vagus suggests that the neuropeptides studied here could be involved in emesis and in cardiovascular/respiratory mechanisms.

\section{Neuropeptides in the alpaca brainstem}

In the alpaca brainstem, the presence of immunoreactive structures containing leucine-enkephalin, calcitonin gene-related peptide, neurotensin, somatostatin, alpha-neo-endorphin, beta-endorphin or adrenocorticotropic hormone has been previously reported [17-20, 22]. Peptidergic immunoreactive fibers (including those containing SP or MET) showed a widespread distribution in the whole brainstem. In addition, the location of the previous nine neuropeptides is similar. Thus, in many nuclei of the alpaca mesencephalon, pons and medulla oblongata (e.g., laminar spinal trigeminal nucleus, parvocellular division of the alaminar spinal trigeminal nucleus, medial division of the facial nucleus, marginal nucleus of the brachium conjunctivum, nucleus of the solitary tract, periaqueductal gray, superior colliculus, substantia nigra), the presence of immunoreactive fibers containing the nine neuropeptides has been reported [17-20, 22]. Although the distribution of the peptidergic fibers observed in the alpaca brainstem is widespread, it is important to note that in most of the brainstem nuclei single fibers containing beta-endorphin or adrenocorticotropic hormone were observed [22]. To date, our study shows the most widespread presence of peptidergic cell bodies found in the alpaca brainstem: MET-immunoreactive perikarya were located in 22 nuclei. No immunoreactive cell body containing alpha-neo-endorphin, beta-endorphin or adrenocorticotropic hormone has been reported in the alpaca brainstem [22]. Peptidergic immunoreactive cell bodies containing somatostatin or calcitonin gene-related peptide were observed in 13 and 12 brainstem nuclei, respectively; those containing neurotensin in five of them and those containing SP or leucine-enkephalin in two brainstem nuclei [17-20]. In the periaqueductal gray and in the reticular formation, the presence of five neuropeptides (leucine-enkephalin, somatostatin, neurotensin, MET, calcitonin gene-related peptide or SP) has been observed in cell bodies [17-20]. Because colchicine was not used in this and previous studies, it seems that the distribution of the peptidergic cell bodies in the alpaca brainstem may be more widespread. To know this distribution, other neuroanatomical studies applying for example in situ hybridization techniques should be performed.

\section{SP and MET in the mammalian brainstem}

Many studies focused on the distribution of SP and MET in the mammalian brainstem have been carried out $[1,2,10-13,25,35,36]$. In general, the widespread distribution of the MET-immunoreactive fibers found in the alpaca brainstem is quite similar to that reported in other mammals in the same CNS region. However, some differences occur. The presence of fibers containing MET was similar in the alpaca, minipig [10] and monkey [25] brainstem and this distribution was a slight more widespread than that found in the dog [13] brainstem. Many differences can be observed when comparing the location of the MET-immunoreactive perikarya in the mammalian brainstem. These differences are due to the methodology applied (administration of colchicine; as indicated above, this drug is used to increase the number of peptidergic cell bodies). In general, in animals treated with colchicine a widespread presence of immunoreactive cell bodies was observed. For example, in rats [37] and dogs [13] treated with colchicine, a widespread distribution of 
cell bodies containing MET was observed in both species. However, here, this widespread distribution was not observed in the brainstem of alpacas not treated with colchicine. When comparing the presence of MET-immunoreactive perikarya in the brainstem of animals not treated with colchicine, for example, alpaca, minipig and monkey [10,25], this distribution was also different. In this case, the alpaca brainstem showed a more widespread distribution of cell bodies containing MET than that observed in the minipig [10] and the latter species showed a more widespread distribution than that found in the monkey brainstem [25]. In summary, in comparison with other mammals, the presence of MET-immunoreactive cell bodies is moderate in the alpaca brainstem (MET-immunoreactive perikarya were observed in 22 of the 44 brainstem nuclei of the alpaca). Finally, in the alpaca and human brainstem, the presence of SP-immunoreactive fibers was widespread and similar, whereas the distribution of perikarya containing SP was a slightly more widespread in humans [38].

In summary, this study increases the knowledge on the neuroanatomical distribution of the tachykininergic (SP) and enkephalinergic (MET) peptidergic systems in the alpaca brainstem. SP- and MET-immunoreactive fibers showed a widespread and similar distribution in the brainstem. This close neuroanatomical relationship suggests multiple physiological interactions between both neuropeptides. The presence of cell bodies containing SP was very restricted, whereas MET-immunoreactive perikarya showed a moderate widespread distribution in the mesencephalon, pons and medulla oblongata. The mapping of SP and MET will help to understand their functional relationships with other neuropeptides previously studied in the alpaca brainstem and this knowledge will serve to better understand the involvement of the peptidergic systems in multiple brainstem physiological functions (e.g., the adaptation to a high altitude). Moreover, our study increases the knowledge on the peptidergic chemical neuroanatomy (enkephalinergic and tachykininergic systems) in the alpaca CNS, since as indicated above, the presence of both neuropeptides has previously been reported in the alpaca diencephalon [5].

\section{Acknowledgements}

The authors wish to thank Professor Gérard Tramu (Université de Bordeaux I, Bordeaux, France) for the gift of primary antibodies and the Language Service of the Universidad de Salamanca (Spain) for supervising the English text. This work has been supported by "Programa XI: Financiación de Unidades de Excelencia de la Universidad de Salamanca" (Spain).

\section{References}

1. Coveñas R, Belda M, Marcos P, et al. Neuropeptides in the cat brainstem. Curr Top Pept Protein Res. 2003; 5: 41-61.

2. Graefe S, Mohiuddin SS. Biochemistry, substance P. StatPearls Publishing: Treasure Island; 2021., indexed in Pubmed: 32119470.

3. Ebner K, Muigg P, Singewald G, et al. Substance P in stress and anxiety: NK-1 receptor antagonism interacts with key brain areas of the stress circuitry. Ann N Y Acad Sci. 2008; 1144: 61-73, doi: 10.1196/annals.1418.018, indexed in Pubmed: 19076365 .

4. Mashaghi A, Marmalidou A, Tehrani M, et al. Neuropeptide substance $\mathrm{P}$ and the immune response. Cell Mol Life Sci. 2016; 73(22): 4249-4264, doi: 10.1007/s00018-016-2293-z, indexed in Pubmed: 27314883.

5. Sánchez P, Sánchez ML, Mangas A, et al. A close neuroanatomical relationship between the enkephalinergic (methionine-enkephalin) and tachykininergic (substance P) systems in the alpaca diencephalon. Folia Histochem Cytobiol. 2020; 58(2): 135-146, doi: 10.5603/FHC.a2020.0007, indexed in Pubmed: 32412087.

6. Duque-Díaz E, Coveñas R. Distribution of somatostatin-28 (1-12), calcitonin gene-related peptide, and substance $P$ in the squirrel monkey brainstem: an immunocytochemical study. Anat Sci Int. 2019; 94(1): 86-100, doi: 10.1007/s12565-0180453-y, indexed in Pubmed: 30051271.

7. Polgár E, Bell AM, Gutierrez-Mecinas M, et al. Substance P-expressing neurons in the superficial dorsal horn of the mouse spinal cord: insights into their functions and their roles in synaptic circuits. Neuroscience. 2020; 450: 113-125, doi: 10.1016/j.neuroscience.2020.06.038, indexed in Pubmed: 32634530 .

8. Luu A, Oberdoerster Z, Grignol G, et al. Presence of substance $P$ positive terminals on hypothalamic somatostatinergic neurons in humans: the possible morphological substrate of the substance P-modulated growth hormone secretion. Brain Struct Funct. 2020; 225(1): 241-248, doi: 10.1007/s00429-01901990-x, indexed in Pubmed: 31807924.

9. Peinado JR, Li H, Johanning K, et al. Cleavage of recombinant proenkephalin and blockade mutants by prohormone convertases 1 and 2: an in vitro specificity study. J Neurochem. 2003; 87(4): 868-878, doi: 10.1046/j.1471-4159.2003.02043.x, indexed in Pubmed: 14622118.

10. Sánchez ML, Vecino E, Coveñas R. Distribution of methionine-enkephalin in the minipig brainstem. J Chem Neuroanat. 2013; 50-51: 1-10, doi: 10.1016/j.jchemneu.2013.03.002, indexed in Pubmed: 23538385.

11. Duque E, Mangas A, Díaz-Cabiale Z, et al. Neuropeptides in the monkey brainstem. In: Williams RM, ed. Monkeys: Biology, Behavior and Disorders. Nova Science Publisher: New York; 2011: 151-166.

12. Marcos P. Neuropeptides in the cat brainstem. In: Coveñas R, Mangas A, Narváez JA, eds. Focus on Neuropeptide Research. Transworld Research Network: Trivandrum; 2007: 57-101.

13. Pesini P, Pego-Reigosa R, Tramu G, et al. Distribution of met-enkephalin immunoreactivity in the diencephalon and the brainstem of the dog. J Chem Neuroanat. 2000; 19(4): 243-258, doi: 10.1016/s0891-0618(00)00071-5, indexed in Pubmed: 11036241.

14. Cullen JM, Cascella M. Physiology, enkephalin. StatPearls Publishing: Treasure Island; 2021, indexed in Pubmed: 32491696. 
15. Ratto MH, Huanca W, Singh J, et al. Local versus systemic effect of ovulation-inducing factor in the seminal plasma of alpacas. Reprod Biol Endocrinol. 2005; 3: 29, doi: 10.1186/14777827-3-29, indexed in Pubmed: 16018817.

16. Ratto M, Huanca W, Singh J, et al. Comparison of the effect of natural mating, $\mathrm{LH}$, and $\mathrm{GnRH}$ on interval to ovulation and luteal function in llamas. Anim Reprod Sci. 2006; 91(34): 299-306, doi: 10.1016/j.anireprosci.2005.03.015, indexed in Pubmed: 15896931.

17. de Souza, Yi P, Aguilar LA, et al. et al. Mapping of leucine-enkephalin in the alpaca (Lama pacos) brainstem. In: Coveñas R, Mangas A, Narváez JA, eds. Focus on Neuropeptide Research. Transworld Research Network: Trivandrum; 2007: 103-114.

18. de Souza E, Coveñas R, Yi P, et al. Mapping of CGRP in the alpaca (Lama pacos) brainstem. J Chem Neuroanat. 2008; 35(4): 346-355, doi: 10.1016/j.jchemneu.2008.02.004, indexed in Pubmed: 18420379.

19. de Souza E, Aguilar LA, Díaz-Cabiale Z, et al. Mapping of neurotensin in the alpaca (Lama pacos) brainstem. Anat Histol Embryol. 2014; 43(4): 245-256, doi: 10.1111/ahe.12067, indexed in Pubmed: 23692174.

20. de Souza E, Sánchez ML, Aguilar LA, et al. Mapping of somatostatin-28 (1-12) in the alpaca (Lama pacos) brainstem. Microsc Res Tech. 2015; 78(5): 363-374, doi: 10.1002/ jemt.22482, indexed in Pubmed: 25754727.

21. Marcos P, Arroyo-Jiménez MM, Lozano G, et al. Mapping of tyrosine hydroxylase in the alpaca (Lama pacos) brainstem and colocalization with CGRP. J Chem Neuroanat. 2011; 41(2): 63-72, doi: 10.1016/j.jchemneu.2010.10.002, indexed in Pubmed: 21050884.

22. Sánchez ML, de Souza E, Aguilar LA, et al. Distribution of alpha-neoendorphin, ACTH (18-39) and beta-endorphin (1-27) in the alpaca brainstem. Anat Histol Embryol. 2018; 47(5): 481-492, doi: 10.1111/ahe.12387, indexed in Pubmed: 30027642 .

23. Sánchez ML, Mangas A, Medina LE, et al. Immunohistochemical mapping of neurotensin in the alpaca diencephalon. Folia Histochem Cytobiol. 2018; 56(1): 49-58, doi: 10.5603/ FHC.a2018.0003, indexed in Pubmed: 29516445.

24. Marcos P, Coveñas R, Narváez JA, et al. Immunohistochemical mapping of enkephalins, NPY, CGRP, and GRP in the cat amygdala. Peptides. 1999; 20(5): 635-644, doi: 10.1016/ s0196-9781(99)00018-2, indexed in Pubmed: 10465517.

25. Duque-Díaz E, Díaz-Cabiale Z, Narváez JA, et al. Mapping of enkephalins and adrenocorticotropic hormone in the squirrel monkey brainstem. Anat Sci Int. 2017; 92(2): 275-292, doi: 10.1007/s12565-016-0333-2, indexed in Pubmed: 26897373.

26. Samsam M, Coveñas R, Csillik B, et al. Depletion of substance $\mathrm{P}$, neurokinin $\mathrm{A}$ and calcitonin gene-related peptide from the contralateral and ipsilateral caudal trigeminal nucleus following unilateral electrical stimulation of the trigeminal ganglion; a possible neurophysiological and neuroanatomi- cal link to generalized head pain. J Chem Neuroanat. 2001; 21(2): 161-169, doi: 10.1016/s0891-0618(01)00088-6, indexed in Pubmed: 11312057.

27. Nusbaum M, Blitz D, Marder E. Functional consequences of neuropeptide and small-molecule co-transmission. Nature Rev Neurosci. 2017; 18(7): 389-403, doi: 10.1038/nrn.2017.56, indexed in Pubmed: 28592905.

28. Martins I, Tavares I. Reticular formation and pain: the past and the future. Front Neuroanat. 2017; 11: 51, doi: 10.3389/ fnana.2017.00051, indexed in Pubmed: 28725185.

29. Yoshida W, Seymour B, Koltzenburg M, et al. Uncertainty increases pain: evidence for a novel mechanism of pain modulation involving the periaqueductal gray. J Neurosci. 2013; 33(13): 5638-5646, doi: 10.1523/JNEUROSCI.4984-12.2013, indexed in Pubmed: 23536078.

30. Blair HT, Cho J, Sharp PE. Role of the lateral mammillary nucleus in the rat head direction circuit: a combined single unit recording and lesion study. Neuron. 1998; 21(6): 1387-1397, doi: 10.1016/s0896-6273(00)80657-1, indexed in Pubmed: 9883731.

31. Bast N, Boxhoorn S, Supér H, et al. Atypical arousal regulation in children with autism but not with attention-deficit/ hyperactivity disorder as indicated by pupillometric measures of locus coeruleus activity. Biol Psychiatry Cogn Neurosci Neuroimaging. 2021, doi: 10.1016/j.bpsc.2021.04.010, indexed in Pubmed: 33930603.

32. Gong L, Shi M, Wang J, et al. The abnormal functional connectivity in the locus coeruleus-norepinephrine system associated with anxiety symptom in chronic insomnia disorder. Front Neurosci. 2021; 15: 678465, doi: 10.3389/fnins.2021.678465, indexed in Pubmed: 34093121.

33. James T, Kula B, Choi S, et al. Locus coeruleus in memory formation and Alzheimer's disease. Eur J Neurosci. 2020 [Epub ahead of print], doi: 10.1111/ejn.15045, indexed in Pubmed: 33190318.

34. Basso MA, Bickford ME, Cang J. Unraveling circuits of visual perception and cognition through the superior colliculus. Neuron. 2021; 109(6): 918-937, doi: 10.1016/j.neuron.2021.01.013, indexed in Pubmed: 33548173.

35. Duque-Díaz E, Alvarez-Ojeda O, Coveñas R. Enkephalins and ACTH in the mammalian nervous system. Vitam Horm. 2019; 111: 147-193, doi: 10.1016/bs.vh.2019.05.001, indexed in Pubmed: 31421699.

36. Muñoz M, Coveñas R. Substance P. Encyclopedia of endocrine diseases. 2018: 571-578, doi: 10.1016/b978-0-12-8012383.95886-0.

37. Palkovits M. Neuropeptides in the brain. In: Ganong WF, Martini L, eds. Frontiers in Neuroendocrinology. Raven Press, New York: 1-44.

38. Bouras C, Vallet PG, Dobrinov H, et al. Substance P neuronal cell bodies in the human brain: complete mapping by immunohistofluorescence. Neurosci Lett. 1986; 69(1): 31-36, doi: 10.1016/0304-3940(86)90409-x, indexed in Pubmed: 2427977.

Submitted: 24 April, 2021

Accepted after reviews: 6 July, 2021 Available as AoP: 26 July, 2021 